\title{
Avaliação de livros digitais com base na Teoria Cognitiva do Aprendizado Multimídia e modelo de análise tipográfico - Estudo de Caso: "A canção dos Pássaros"
}

\author{
Evaluation of digital books based on the Cognitive Theory of Multimedia Learning \\ and model of typographic analysis - Case Study: "A canção dos Pássaros"
}

Thaís Lemos Lima, Cássia Cordeiro Furtado \& Arthur José Silva Marques

design da Informação, TCAM, tipografia

\begin{abstract}
Este trabalho faz um estudo de caso do livro digital "A canção dos Pássaros", disponível no website Kidsbook Itaú Criança. O estudo faz uma avaliação do ebook com base em alguns princípios da Teoria Cognitiva da Aprendizagem Multimídia, de Richard Mayer (2003), e no modelo de análise tipográfica, de Priscila Farias (2016). O trabalho revela alguns pontos que poderiam ser melhorados e como eles podem afetar no processo de leitura do público infantil.
\end{abstract}

\section{Informational design, CTML, typography}

This paper makes a case study of the digital book "A canção dos Pássaros", available on the Kidsbook Itaú Criança website. The study evaluates the ebook based on some principles of Richard Mayer's (2003) Cognitive Theory of Multimedia Learning and Priscila Farias's (2016) typographic analysis model. The work reveals some points that could be improved and how they can affect the process of reading the children's audience.

\section{Introdução}

A procura por obras digitais tem contribuído com o aumento em sua relevância no cenário literário e editorial. A inclusão da categoria Infantil Digital desde 2015 no Prêmio Jabuti, um dos mais tradicionais prêmios literários do Brasil, é um exemplo dessa ascensão.

Todavia, considerando o perfil previsto para a emergente terceira geração de nativos digitais, denominada Alpha, é compreensível o crescimento do mercado de livros digitais (ebooks) infantis. Essa correspondência pode ser resultado da familiaridade que os pequenos leitores, deste grupo social, possuem com a tecnologia de telas.

Além disso, devido a tal afinidade com os recursos tecnológicos, Flynn (2012) estima o aumento da capacidade cognitiva desses indivíduos. Por isso, ao tratar de livros digitais infantis é possível inferir que são objetos que transcendem o caráter tecnológico, pois possuem também o objetivo da leitura. Nessas perspectivas, tem-se esse último como um exercício que pode contribuir no desenvolvimento perceptivo da criança, em decorrência dos signos e símbolos visuais presentes em livros (Caldin, 2003). Portanto, é importante ressaltar a prática da leitura na infância como um processo de desenvolvimento cognitivo e aprendizado.

Alinhado a isso, Gonçalves, Barbosa e Silva (2018) evidenciam em sua pesquisa que a materialização do objeto "livro" interfere direta e indiretamente nos modos de leitura, apropriação e geração de sentido. Portanto, ler em uma tela é uma experiência que se difere da leitura de impressos.

Por isso, faz-se necessário compreender as condições adequadas para confecção de uma obra literária que pode, segundo Sargeant (2013), prover ao leitor uma experiência repleta de diferentes estímulos multissensoriais. Vale ressaltar que, por se tratar de uma produção que acompanha o desenvolvimento tecnológico, ainda não se chegou à um resultado com parâmetros de avaliação consolidados (Lima \& Lessa, 2014; Ladeira, Obregon \& Ulbricht,

Anais do 9 CIDI e 9 CONGIC

Luciane Maria Fadel, Carla Spinillo, Anderson Horta,

Cristina Portugal (orgs.)

Sociedade Brasileira de Design da Informação - SBDI

Belo Horizonte | Brasil | 2019

ISBN 978-85-212-1728-2
Proceedings of the 9th CIDI and 9th CONGIC

Luciane Maria Fadel, Carla Spinillo, Anderson Horta,

Cristina Portugal (orgs.)

Sociedade Brasileira de Design da Informação - SBDI

Belo Horizonte | Brazil | 2019

ISBN 978-85-212-1728-2 
Lima, T. L., Furtado, C. C. \& Marques, A. J. S. | Avaliação de livros digitais com base na Teoria Cognitiva do Aprendizado Multimídia e modelo de análise tipográfico - Estudo de Caso: "A canção dos Pássaros"

2017). Por essa razão, a importância do estudo desse tipo de produção ainda é evidenciada por alguns autores.

\section{Compreensão na Leitura Multimodal}

Com "compreensão" tem-se o significado de decodificação e apreensão de conteúdos por meio da leitura em múltiplas camadas, pois, conforme Rosa (2016), o exercício da leitura pode ser atribuído ao raciocínio das palavras e seus significados, assim como à capacidade de interpretar a informação lida e relacioná-la com o conhecimento prévio do leitor. Desta forma, faz-se um processo incessante de construção e ressignificação do material lido.

Ademais, ao utilizar o termo "leitura multimodal" é levado em consideração o uso dos diversos sistemas sensoriais (Moreno \& Mayer, 2007) que podem estar presentes em livros digitais interativos. Sendo assim, essa atividade deixa de ser exercida apenas no campo das palavras, mas também pode ser percebida na leitura das animações, nas imagens e dos sons dos ebooks.

Nesse sentido, Grimshaw, Dungworth, McKnight e Morris (2007) comentam a utilização desses recursos podem contribuir na compreensão do texto pois podem ajudar a distribuir o esforço de decodificação, que normalmente seria atribuído somente às palavras, e permite que a criança foque no sentido como um todo. No entanto, ainda assim é necessário que processos relacionados ao reconhecimento das palavras ocorram primeiro para alcançar um nível adequado de apreensão do conteúdo proposto.

Esses princípios evidenciam que a percepção significativa da história narrada acontece em etapas de significação distintas. Por causa disso, Rosa (2016) evidencia a importância da atenção durante a leitura. Segundo a autora, o cérebro humano não é dotado da capacidade de decodificar múltiplos estímulos sensoriais simultaneamente, pelo contrário, é preciso que haja uma focalização e concentração da consciência.

Portanto, a estruturação das informações nesse formato de publicação é um ponto relevante do projeto de design, pois segundo Silva, Pinho Neto e Dias (2013), se essa intensidade de conteúdos for gerada sem critérios mais rígidos de organização, filtro e controle de qualidade da informação, podem levar à desinformação. De maneira similar, Rosa (2016) afirma que a memorização de uma história pode ser prejudicada quando a organização do texto não está de acordo com a estrutura informacional em que é inserido.

Nesse sentido, é notória a importância de a narrativa multimodal ter relevância para a construção da história, tal forma que os recursos de áudio, vídeo e imagem sejam empregados com finalidades além do entretenimento.

\section{Processamento da Informação e Aprendizagem}

Se tratando de livros digitais infantis, a leitura deixa de ser uma atividade passiva e pode ganhar a características de multimodal e interativa. Multimodal, nesse sentido, se refere aos diferentes sistemas sensoriais necessários para compreender as informações verbais e visuais (multimídia), no caso, o visual e o auditivo (Moreno \& Mayer, 2007). Normalmente esses conteúdos multimídia são apresentadas por meio de ilustrações, animações, textos e narração.

No entanto, apesar de alguns autores, como Menegazzi (2018) e Grimshaw et al (2007), apontarem que o uso desses recursos pode estimular diversas áreas de percepção do leitor, Sargeant (2013) e Mayer (2003) acusam que o mal-emprego deles pode ocasionar um excesso de informações, podem causar um excesso de informações e levar a uma sobrecarga cognitiva. Consequentemente, o usuário do livro digital por se desconcentrar e se desconectar da narrativa central do livro (Sargeant, 2013).

Nesse contexto, Richard Mayer (2003) desenvolveu a Teoria Cognitiva da Aprendizagem Multimídia (TCAM). De maneira geral, é baseada em três suposições: o canal duplo, a capacidade limitada do aprendiz e o processamento ativo. Primeiramente, quanto ao canal duplo, o autor explica que existem dois canais de processamento da informação: o primeiro é o canal verbal, que capta a entrada de texto escrito ou falado (narração) por meio do sentido auditivo; já o segundo é o canal visual, que percebe a entrada de imagens e animações por 
Lima, T. L., Furtado, C. C. \& Marques, A. J. S. | Avaliação de livros digitais com base na Teoria Cognitiva do Aprendizado Multimídia e modelo de análise tipográfico - Estudo de Caso: "A canção dos Pássaros"

intermédio da visão. Todavia, Mayer (2003) ressalta que palavras escritas, por possuírem uma representação gráfica, podem ser processadas também pelo canal visual.

Assim, após a entrada de informação, há a seleção de palavras e imagens relevantes, que são processadas, organizadas e convertidas em representações mentais de modelos verbais e pictóricos, que são integrados ao conhecimento prévio do aprendiz. O resultado dessa aprendizagem é armazenado na memória de longa duração (Mayer, 2003). Esse processo pode ser não-linear, com a presença de retornos e avanços consecutivos.

Figura 1: Esquema da Teoria Cognitiva da Aprendizagem Multimídia (Adaptado de Mayer, 2003)

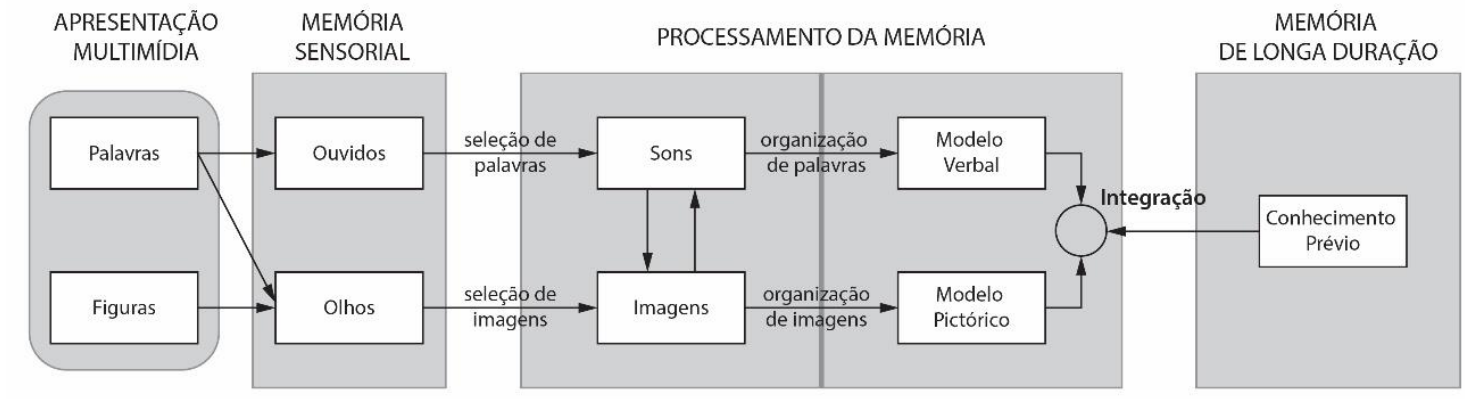

No que diz respeito às outras suposições supracitadas, o autor entende que a capacidade de aprendizado do estudante é limitada e com processamento ativo, o autor se refere à condição do aprendizado atribuído ao nível de atenção que o indivíduo detém (Mayer, 2003).

Partindo dessa teoria, Mayer (2014) descreveu sete princípios que podem ser adaptados para a avaliação de ebooks, devido a presença de elementos semelhantes como: animação, narração e texto verbal presentes em tela, e são eles os princípios da multimídia, da contiguidade espacial, da contiguidade temporal, da coerência, da modalidade, da redundância e da personalização.

\section{Objetivo}

O objetivo é avaliar as configurações do livro digital interativo, em relação aos princípios descritos por Mayer (2014) e à análise dos elementos da linguagem gráfica verbal presente no livro.

\section{Métodos}

Foi escolhido um livro digital do website Kidsbook Itaú Criança, que recebeu o prêmio Jabuti na categoria Digital Infantil, em 2017. Dentro da plataforma, foi selecionado "A canção dos pássaros", escrito por Zeca Baleiro e ilustrado por Herbert Loureiro, que aparece como capa da página principal do site.

Apesar de não possuir uma divisão de páginas numeradas devido à característica de navegação por barra de rolagem, é possível observar uma delimitação entre as ilustrações. Esses limites das ilustrações serão considerados para marcação das páginas do livro. A última página não foi considerada para a amostra final pois é uma página adicional, com um jogo de karaokê e não interfere na história central do livro digital (Figura 2). 
Lima, T. L., Furtado, C. C. \& Marques, A. J. S. | Avaliação de livros digitais com base na Teoria Cognitiva do Aprendizado Multimídia e modelo de análise tipográfico - Estudo de Caso: "A canção dos Pássaros"

Figura 2: Paginação considerada para a pesquisa
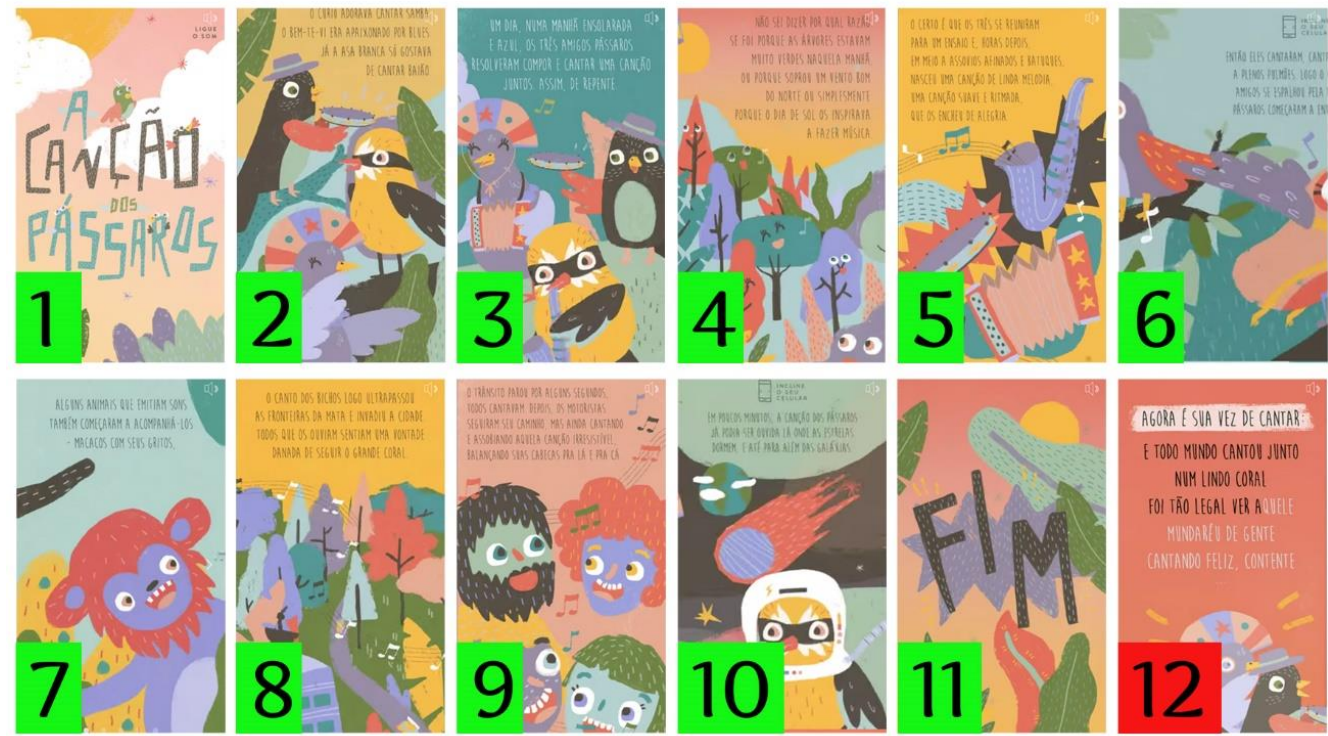

Nesse sentido, dos sete princípios de design informacional presentes na TCAM, cinco foram utilizados e adaptados para analisar o livro digital. São eles os princípios da multimídia, da coerência, da contiguidade espacial, da contiguidade temporal, da redundância, da modalidade (Quadro 1) (Mayer, 2003; Moreno \& Mayer, 2007; Mayer, 2014).

- Multimídia: A relação texto (escrito ou falado) com imagem é mais eficiente na retenção de informação do que o texto isolado.

- Coerência: Eliminação de detalhes irrelevantes.

- Contiguidade Espacial: é preferível que textos e imagens relacionadas estejam próximos um do outro.

- Modalidade: o uso de imagem com narração é melhor que imagem com texto. Essa última combinação pode causar sobrecarga de processamento.

- Redundância: é preferível que se escolha a combinação imagem com narração, do que o uso de texto com imagem e texto falado, pois pode gerar uma sobrecarga de processamento.

Quadro 1: Quadro de avaliação gerado a partir da TCAM de Richard Mayer.

\begin{tabular}{|l|l|l|l|l|}
\hline \multicolumn{1}{|c|}{ Princípios da TCAM } & Atende & $\begin{array}{c}\text { Atende } \\
\text { Parcial- } \\
\text { mente }\end{array}$ & $\begin{array}{c}\text { Não } \\
\text { Atende }\end{array}$ & COMENTÁRIOS \\
\hline Multimídia & & & & \\
\hline Coerência & & & & \\
\hline Contiguidade Espacial & & & & \\
\hline Modalidade & & & & \\
\hline Redundância & & & & \\
\hline
\end{tabular}

Para avaliação das características tipográficas do texto, foi realizada uma análise baseada no modelo de análise tipográfica de Priscila Farias (2016), baseada nos conceitos da semiótica de Charles Sanders Peirce. 
Lima, T. L., Furtado, C. C. \& Marques, A. J. S. | Avaliação de livros digitais com base na Teoria Cognitiva do Aprendizado Multimídia e modelo de análise tipográfico - Estudo de Caso: "A canção dos Pássaros"

Parte-se da compreensão da tipografia em um sentido amplo, que inclui o design de letras e o design com letras, independentemente do modo de produção ou reprodução. Tal definição inclui, portanto, manifestações da linguagem gráfica verbal que, de um ponto de vista mais restrito, seriam mais bem descritos como escrita ou letreiramento. (Farias, 2016, p. 46).

Para este trabalho foi considerada apenas a dimensão sintática e como algumas das características podem influenciar no processo de leitura do ebook, conforme avaliação dos itens a seguir (Farias, 2016):

- Letra: tamanho, proporções, estrutura (caixa), forma, cor;

- Palavra: direção, alinhamento, continuidade/segmentação, variação (forma ou estrutura), espaço entre letras, elementos, associados;

- Texto: largura da coluna, espaço entre palavras, alinhamento, entrelinha, tonalidade da mancha de texto, recuos, marcação de linhas, bloco de texto;

- Página: grade, alinhamento dos blocos de texto, hierarquia, relação blocos de texto $\times$ imagens, elementos demarcadores de blocos de texto;

- Volume: aspectos materiais, aspectos dinâmicos, quantidade de páginas, sistema de gravação ou reprodução, relação entre partes do volume.

Além disso, do ponto de vista do Design da Informação, a facilidade de leitura é diretamente proporcional ao "conforto visual" e ao entendimento da estrutura do texto (Petterson, 2015). Dessa forma, para esse trabalho foi utilizado algumas premissas para aprofundar a avaliação tipográfica:

- O uso da caixa alta em textos longos pode reduzir a velocidade do fluxo de leitura (Petterson, 2015);

- Textos alinhados à esquerda podem causar interferências no fluxo de leitura (Bringhurst, 2011);

- O espaço entre-letras está diretamente relacionado à legibilidade das letras tipográficas (Bringhurst, 2011);

- É importante que haja uma homogeneidade de espaçamento-palavras. Por essa razão, é preferível um texto alinhado à esquerda (garantindo menos rigidez à página e evitando excesso de hifens), que um texto justificado com o espaçamento desbalanceado (Bringhurst, 2011);

- O uso de cores pode contribuir para reforçar a estrutura do texto (Petterson, 2015);

- Sentenças de texto longas e complexas tendem a exigir mais da capacidade cognitiva do leitor (Petterson, 2015);

Finalmente, uma informação adicional, comentada por Gonçalves et al (2018), diz que uma característica presente na maioria dos livros digitais é a falta de indicativos sobre o progresso da leitura. Desta forma, o leitor perde a referência do quanto já foi lido e quantas páginas faltam para terminar a leitura. Segundo os autores, essa característica pode causar incômodo a alguns leitores, pois este perde sua localização no corpo da obra. Por isso, essa característica também fará parte da avaliação do livro digital "A canção dos pássaros".

\section{Resultados}

A partir da análise dos recursos multimídia, foi possível constatar que, de forma geral, o livro digital não atende à maioria dos princípios da TCAM de Mayer, com exceção do Princípio da Multimídia, que é atendido em todas as páginas. O problema que mais chamou atenção foi a entrada simultânea do texto e da música que toca ao fundo. Conforme já mencionado previamente, a entrada de texto escrito e falado são recebidas pelo mesmo canal de processamento e, portanto, essa dupla entrada pode causar uma sobrecarga no canal de

Anais do 9 Congresso Internacional de Design da Informação | CIDI 2019 
Lima, T. L., Furtado, C. C. \& Marques, A. J. S. | Avaliação de livros digitais com base na Teoria Cognitiva do Aprendizado Multimídia e modelo de análise tipográfico - Estudo de Caso: "A canção dos Pássaros"

processamento de informação verbal (Mayer, 2003; Moreno \& Mayer, 2007).

Além disso, na página 2, existe uma confusão entre a letra da canção e o que está escrito: ambas as frases possuem começos parecidos e palavras similares em suas composições. Por se tratar da primeira página com corpo de texto, esse conflito pode levar o leitor a entender que a canção é, na verdade, a narração da história. Essa dupla entrada verbal pode prejudicar o processo de leitura de uma criança em fase de alfabetização, visto que irão tentar relacionar narração e texto (Figura 3).

Figura 3: Semelhanças entre texto escrito e canção

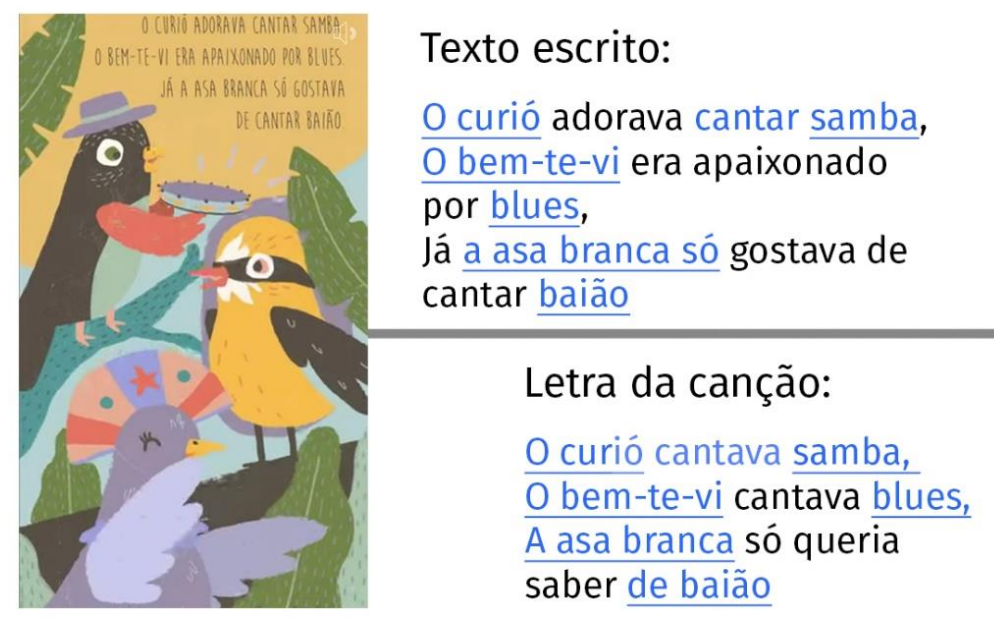

O livro "A canção dos Pássaros", também apresenta navegação por barra de rolagem pode contribuir com a perda da noção de avanço no conteúdo do livro. Ademais, um outro problema encontrado devido a essa configuração é que em alguns momentos a transição entre páginas não é sutil e é possível ouvir os sons da página seguinte antes de realmente acessá-la por completo.

Figura 4: Movimento horizontal em posição ideal para leitura na página 6.

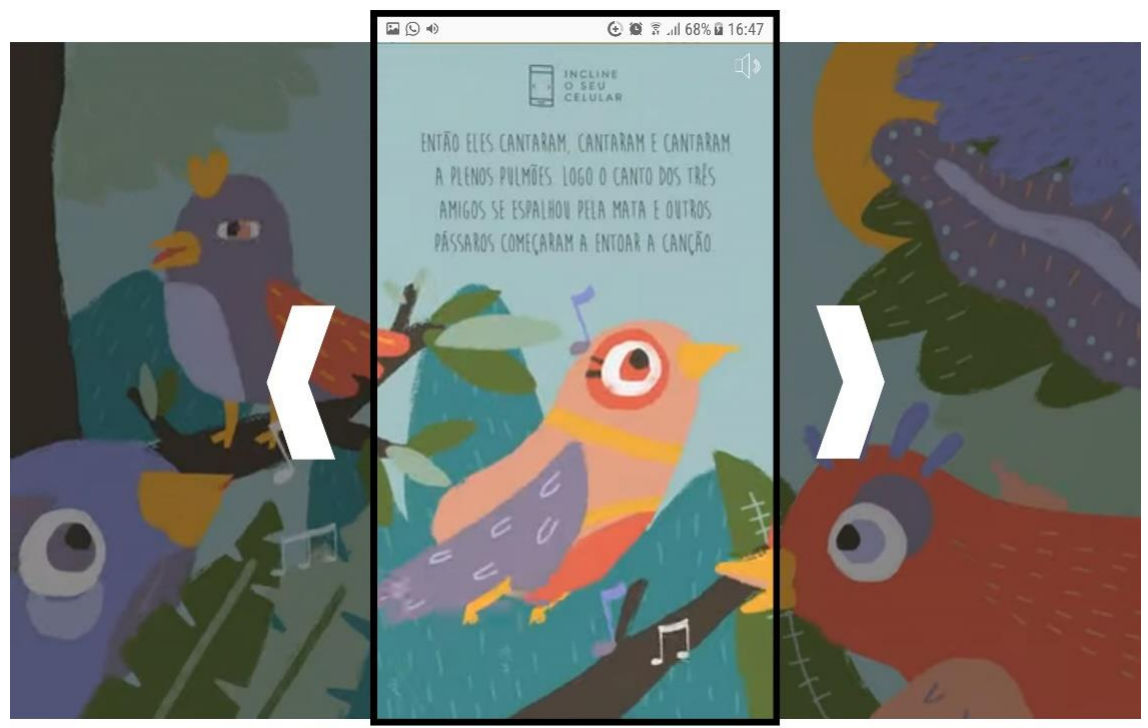

Nas páginas 6 e 10 existe um problema quanto à interação aplicada a elas. Existe uma

Anais do 9ำ Congresso Internacional de Design da Informação | CIDI 2019 
Lima, T. L., Furtado, C. C. \& Marques, A. J. S. | Avaliação de livros digitais com base na Teoria Cognitiva do Aprendizado Multimídia e modelo de análise tipográfico - Estudo de Caso: "A canção dos Pássaros"

sensibilidade ao movimento do dispositivo nessas páginas (Figura 4), que permite uma navegação horizontal. Esse recurso interativo pode comprometer a visualização do texto pois o aparelho utilizado para reprodução do livro digital precisa estar num local que deixe seu posicionamento estável, do contrário a página fica se movendo constantemente.

O quadro síntese das avaliações de cada página pode ser observado no Quadro 2. Nele é possível constatar os comentários acerca de cada página do livro.

Quadro 2: Síntese dos Resultados após análise dos Princípios da TCAM.

\begin{tabular}{|c|c|c|c|c|c|c|c|c|c|c|c|c|c|c|c|c|}
\hline \multirow{3}{*}{ PÁGINAS } & \multicolumn{15}{|c|}{ PRINCÍPIOS } & \multirow{3}{*}{ COMENTÁRIOS } \\
\hline & \multicolumn{3}{|c|}{ MULT. } & \multicolumn{3}{|c|}{ COER. } & \multicolumn{3}{|c|}{ C.E. } & \multicolumn{3}{|c|}{ MOD. } & \multicolumn{3}{|c|}{ RED. } & \\
\hline & $A$ & $P$ & $\mathrm{~N}$ & $A$ & $P$ & $\mathrm{~N}$ & A & $P$ & $\mathrm{~N}$ & $A$ & $P$ & $\mathrm{~N}$ & A & $P$ & $\mathrm{~N}$ & \\
\hline 1 & $x$ & & & & & $\mathrm{x}$ & & $x$ & & \multicolumn{3}{|c|}{--} & \multicolumn{3}{|c|}{-} & $\begin{array}{l}\text { Uso desnecessário da música de } \\
\text { fundo. }\end{array}$ \\
\hline 2 & $x$ & & & & & $\mathrm{X}$ & & $x$ & & & & $x$ & & & $x$ & $\begin{array}{l}\text { Existe um conflito entre a letra da } \\
\text { música e o texto escrito, além da } \\
\text { presença de sons de pássaros que } \\
\text { acontecem simultaneamente. }\end{array}$ \\
\hline 3 & $\mathrm{X}$ & & & & & $\mathrm{x}$ & $x$ & & & & & $x$ & & & $\mathrm{X}$ & $\begin{array}{l}\text { A música os sons de pássaros } \\
\text { cantando podem ser detalhes } \\
\text { necessários. }\end{array}$ \\
\hline 4 & $\mathrm{X}$ & & & & & $\mathrm{x}$ & & $x$ & & & & $x$ & & & $x$ & $\begin{array}{l}\text { O som ambiente é considerado para } \\
\text { o D.I. um elemento desnecessário. }\end{array}$ \\
\hline 5 & $x$ & & & & & $\mathrm{x}$ & & & $x$ & & & $x$ & & & $x$ & $\begin{array}{l}\text { Mais uma vez existe um conflito } \\
\text { entre canção e texto escrito. Além da } \\
\text { presença dos sons de pássaros. }\end{array}$ \\
\hline 6 & $\mathrm{X}$ & & & & & $\mathrm{x}$ & & $\mathrm{x}$ & & & & $x$ & & & $x$ & $\begin{array}{l}\text { Conflito entre canção e texto escrito. } \\
\text { Existe uma interação com o celular } \\
\text { que dificulta a estabilidade da tela, } \\
\text { impedindo, em alguns momentos a } \\
\text { centralização do texto para leitura. }\end{array}$ \\
\hline 7 & $\mathrm{X}$ & & & & & $\mathrm{x}$ & & $x$ & & & & $x$ & & & $x$ & $\begin{array}{l}\text { O uso da música de fundo é } \\
\text { considerado desnecessária. }\end{array}$ \\
\hline 8 & $\mathrm{X}$ & & & & & $\mathrm{x}$ & $x$ & & & & & $x$ & & & $x$ & $\begin{array}{l}\text { O uso da música de fundo é } \\
\text { considerado desnecessária. }\end{array}$ \\
\hline 9 & $\mathrm{X}$ & & & & & $\mathrm{X}$ & & & $x$ & & & $x$ & & & $\mathrm{x}$ & $\begin{array}{l}\text { O uso da música de fundo é } \\
\text { considerado desnecessária. }\end{array}$ \\
\hline 10 & $x$ & & & & & $\mathrm{x}$ & & $x$ & & & & $x$ & & & $\mathrm{X}$ & $\begin{array}{l}\text { Interação com o celular que dificulta } \\
\text { a estabilidade da tela, impedindo, em } \\
\text { alguns momentos a centralização do } \\
\text { texto para leitura. Uso desnecessário } \\
\text { da música de fundo. }\end{array}$ \\
\hline 11 & $x$ & & & & & $\mathrm{x}$ & & - - & & & - - & & & - - & & $\begin{array}{l}\text { Uso desnecessário da música de } \\
\text { fundo. }\end{array}$ \\
\hline
\end{tabular}

Legenda: A - Atende; P - Atende Parcialmente; N - Não Atende; - - (dois traços) - Não aplicável.

Alguns apontamentos adicionais ainda podem ser feitos. O uso de caixa alta em textos longos pode reduzir a velocidade do fluxo de leitura. O contraste texto-figura quase sempre é inadequado nas páginas analisadas, com exceção da página 3. Os traços finos sem variação das letras da tipografia escolhida, não proporciona destaque em relação à animação de fundo, além de alguns sinais de pontuação como a vírgula e o ponto quase desaparecem devido aos seus tamanhos mínimos. Ademais, em algumas páginas foram utilizadas cores análogas às cores das imagens de fundo sendo, assim, outro fator de redução da legibilidade.

Os resultados da avaliação do texto em tela estão descritos no Quadro 3. 
Lima, T. L., Furtado, C. C. \& Marques, A. J. S. | Avaliação de livros digitais com base na Teoria Cognitiva do Aprendizado Multimídia e modelo de análise tipográfico - Estudo de Caso: "A canção dos Pássaros"

Quadro 3: Resultados da análise pelo Modelo de Análise tipográfica de Farias (2016).

\begin{tabular}{|c|c|}
\hline $\begin{array}{l}\text { DIMENSÃO } \\
\text { SINTÁTICA }\end{array}$ & Comentários \\
\hline Letra & $\begin{array}{l}\text { A letra é sem serifa e possui formas irregulares, mimetizando um estilo mais livre de composição. } \\
\text { Possui traços finos e sem variação de espessura entre hastes, traves, braços. São utilizadas apenas } \\
\text { letras em caixa alta, em todo o texto, decisão essa que pode levar ao comprometimento da leitura do } \\
\text { texto. Possui uma proporção constante entre altura e largura das letras. Quanto à cor das letras, com } \\
\text { exceção da página 3, as demais páginas apresentam um baixo contraste entre a cor das letras e a } \\
\text { imagem de animação de fundo, devido ao uso de cores análogas. Sinais de pontuação como a } \\
\text { vírgula e o ponto são quase imperceptíveis devido aos seus tamanhos reduzidos. }\end{array}$ \\
\hline Palavra & $\begin{array}{l}\text { O espaço entre letras é fixo em sua maioria, mas com algumas alterações em encontros como } A \text { e R, } \\
\mathrm{L} \text { e U. O formato assimétrico e irregular das letras pode contribuir com essas variações de espaço } \\
\text { entre letras. }\end{array}$ \\
\hline Texto & $\begin{array}{l}\text { Nas páginas } 5 \text { e } 9 \text { existem o texto alinhado à direita e esse tipo de alinhamento é o mais adequado } \\
\text { para leitura de textos. Nas demais páginas, o texto possui alinhamentos centralizado e à esquerda. } \\
\text { Esses tipos de alinhamento não são recomendados para leitura de textos, no entanto, por se tratares } \\
\text { de trechos curtos, talvez essa configuração não cause muita interferência na leitura. O espaço entre } \\
\text { palavras é fixo, não há presença de recuos, }\end{array}$ \\
\hline Página & $\begin{array}{l}\text { O texto ocupa uma posição hierárquica em relação às animações, sempre localizados no todo das } \\
\text { páginas. Tanto o formato das letras quanto os estilos das ilustrações animadas seguem um padrão de } \\
\text { representação infantil. }\end{array}$ \\
\hline Volume & $\begin{array}{l}\text { São consideradas } 12 \text { páginas no total, se for considerado os limites das ilustrações animadas, mas de } \\
\text { fato, não existe uma separação totalmente demarcada. A reprodução do livro digital se dá por meio } \\
\text { digital, por intermédio do aparelho celular, e a navegação entre páginas se dá pelo uso da barra de } \\
\text { rolagem. }\end{array}$ \\
\hline
\end{tabular}

\section{Conclusões}

O estudo teve como objetivo principal a avaliação das configurações de um livro digital partindo do arcabouço teórico de Mayer (2014), que definia princípios para o aprendizado por meio de elementos multimídia, e uso do modelo de análise tipográfica de Farias (2016) para condução da análise de outros elementos como estrutura do texto e tipografia.

Assim, no livro digital "A canção dos pássaros", do website Kidsbook Itaú Criança, foram encontrados alguns pontos que poderiam ser melhorados do ponto de vista do design da informação. A avaliação com base nos princípios da Teoria Cognitiva do Aprendizado Multimídia levou a constatação de que algumas características do livro, como a presença da canção no fundo com uma letra que conflitava com o texto escrito. Além disso, o uso de animação, canção, som de pássaros, mais texto escrito gerava uma sobrecarga cognitiva, tanto no canal verbal, quanto no visual. Ademais, o ebook também apresentou alguns problemas na escolha da tipografia para o texto, segundo o modelo de avaliação tipográfica utilizado.

No entanto, como já mencionado anteriormente, o formato digital para livros ainda não encontrou sua forma consolidada. Sendo assim, o acompanhamento de pesquisas em design da informação é relevante para que a finalidade básica do livro não seja comprometida: a leitura e formação do ser humano. Portanto, se tratando de um público infantil, essa preocupação com a leiturabilidade e aprendizado da criança é ainda mais importante.

É válido ressaltar que o hábito da leitura na infância vem de encontro com o desenvolvimento cognitivo e crítico da criança, além de ser uma maneira de ensiná-la a decodificar e interagir com o mundo a sua volta. Desta forma, se existem falhas na concepção dos livros digitais, no que diz respeito à forma como são empregadas as informações, os recursos interativos e as características tipográficas do texto, o exercício da leitura pode ser prejudicado. Portanto o acompanhamento de pesquisas em Design da Informação é relevante para que a finalidade básica do livro infantil não seja comprometida: o aprendizado e a formação do ser humano. 
Lima, T. L., Furtado, C. C. \& Marques, A. J. S. | Avaliação de livros digitais com base na Teoria Cognitiva do Aprendizado Multimídia e modelo de análise tipográfico - Estudo de Caso: "A canção dos Pássaros"

\section{Agradecimento}

Agradeço à Fundação de Amparo a Fundação de Amparo à Pesquisa e ao Desenvolvimento Científico e Tecnológico do Maranhão (FAPEMA) por apoiar essa pesquisa e contribuir com sua realização.

\section{Referências}

Bringhurst, R. (2011). Elementos do estilo tipográfico. São Paulo, SP: Cosac Naify.

Caldin, C. F. (2003). A Função Social da Leitura da Literatura Infantil. Encontros Bibli: Revista eletrônica de biblioteconomia e ciência da informação. Florianópolis, SC: Universidade Federal de Santa Catarina. doi: 10.5007/1518-2924.2003v8n15p47

Farias, P. L. (2016). Semiótica e tipografia: apontamentos para um modelo de análise. In: MORAES, D., DIAS, R. A., \& SALES, R. B. C. (Org.). Cadernos de Estudos Avançados em Design: Design e Semiótica. (pp. 176). Barbacena: EdUEMG.

Flynn, J. R. (2012). O que é inteligência? São Paulo, SP: Bookman.

Gonçalves, M. S., Barbosa, R. O., \& Silva, R. P. A. (2018). Mapeando sentidos: texto, materialidade e leitura. In: GRUSZYNSKI, A. C., MARTINS, B. G., \& GONÇALVES, M. S. (Org.). Agentes e Objetos (pp. 394). Belo Horizonte, MG: PPGCOM UFMG.

Grimshaw, S., Dungworth, N., Mcknight, C., \& Morris, A. (2007). Electronic books: children's reading and comprehension. British Journal of Educational Technology. 38(4). 583-599. doi:10.1111/j.1467-8535.2006.00640.

Ladeira, F., Obregon, R. F. A., \& Ulbricht, V. R. (2017). Aplicação do Modelo NormativoDescritivo na Análise de Livros Digitais Multimídia. Revista Tecnologias na Educação, 18, 01-17. Retrieved from: http://tecedu.pro.br/wp-content/uploads/2017/02/Art3-vol18edi\%C3\%A7\%C3\%A3o-tematica-III-I-SNTDE-2016.pdf

Lima, A. B. S., \& Lessa, W. D. (2014). O ebook infantil e as relações texto-imagem-interação. In: Anais do $11^{\circ}$ Congresso Brasileiro de Pesquisa e Desenvolvimento em Design. 1(4), 3263-3274. São Paulo, SP: Blucher.

Mayer, Richard. E. (2003). The promise of multimedia learning: using the same instructional design methods across different media. Learning and Instruction. (13), 125-139. Santa Barbara: Elsevier Science Ltd.

Mayer, Richard E. (2014). The Cambridge Handbook of Multimedia Learning. 2 ed. Santa Barbara: Cambridge University Press.

Mccrindle, Mark. (2014). The ABC of XYZ: understanding the global generations. Bella Vista, NSW: McCrindle Research Pty Ltd.

Menegazzi, Douglas. (2018). O Design de interfaces de livros infantis apps: uma revisão das características e recomendações. Textura - Revista de Educação e Letras. 20(43), 215-239.

Moreno, R., \& Mayer, R. E. (2007). Interactive multimodal learning environments. Springer Link: Educational Psychology Review. 19(3), 309-326.

Petterson, R. (2015). Information Design 2: text design. Viena, Austria: IIID Public Library.

Rosa, G. P. S. (2016). Atenção, compreensão da leitura, consciência textual e aprendizagem. Porto Alegre: Anais do IX Colóquio de Linguística, Literatura e Escrita Criativa. 270284.

Sargeant, B. (2013). Interactive storytelling: how picture book conventions inform multimedia book app narratives. Australian Journal of Intelligent Information Processing Systems, 13(3), 29-34.

Silva, M. A. T., Pinho Neto, J. A. S., \& Dias, G. A. (2013). Arquitetura da Informação para quê e para quem?: uma reflexão a partir da prática em ambientes informacionais digitais.

Anais do 9o Congresso Internacional de Design da Informação | CIDI 2019

Proceedings of the 9th Information Design International Conference

Anais do $9^{\circ}$ Congresso Nacional de Iniciação Científica em Design da Informação | CONGIC 2019

Proceedings of the $9^{\text {th }}$ Information Design Student Conference 
Lima, T. L., Furtado, C. C. \& Marques, A. J. S. | Avaliação de livros digitais com base na Teoria Cognitiva do Aprendizado Multimídia e modelo de análise tipográfico - Estudo de Caso: "A canção dos Pássaros"

Encontros Bibli: revista eletrônica de biblioteconomia e ciência da informação, 18(37), 283-302.

\section{Sobre o(a/s) autor(a/es)}

Thaís Lemos Lima, Mestranda, UFMA, Brasil <thaislemos93@gmail.com>

Cássia Cordeiro Furtado, PhD, UFMA, Brasil <cf.cfurtado@gmail.com>

Arthur José Silva Marques, Mestrando, UFMA, Brasil <arthurgarre@gmail.com> 